\title{
Introduction
}

\section{AN OPEN LETTER TO OUR READERS}

During the evening here in the Northern Hemisphere, I enjoy saying the names of the southern constellations aloud-las Tres Marías, las Tres Pascualas, la Osa Mayor-perhaps because enumerating the stars of my homeland reminds me of my sky and of my experiences, of a past that now has the same destiny as all dreams and memories.

The precariousness of memory, the ambiguity of remembering, along with our obsession for recalling the past have been a central part of our exile in the United States. My mother's final preparation for our journey was to pack hundreds of letters from her childhood into her handbag, correspondence from and to her dear friends, postcards from her family in Vienna. Beautiful letters written in an elegant hand. I could recognize only a few names of those distant cities-Vienna, Prague. We were uncertain if the addressees had passed away from old age or if they had died in the depraved chambers of blue gas. Nonetheless, that miraculous bag filled with graceful words confirmed our past and assured us that our ancestors would be with us at our new destination, North America.

In the same way that my mother managed to survive in distant Chile during World War II by treasuring the letters from her relatives as if they were priceless gems, the reader of this book will discover that this collection of letters written between the years 1965 and 2000 are the jewels of memories shared by two friends who are both similar and distinct, two friends united through their dreams of adolescence and their hope for justice and equality, friends who have chosen parallel pathways in the spiritual journey that they share.

I met Emma Sepúlveda in January 1965 during a steamy summer in the Southern Hemisphere. We encountered one another at the popular seaside resort El Quisco, located an hour's drive from Santiago. As was the custom in those days, the girls would stroll through a district known as El Melocotón. We dressed in white 
and wore a bit of makeup, some of us with too much mascara layered on our lashes and our skin bronzed with the aid of a magical cream called Sunbeam. The more modest girls, or perhaps the most audacious, anointed their bodies with Coca-Cola, as I did.

Emma was a beautiful teenager with long, luxuriant black hair. My fine blond hair was shorter than hers. Suddenly we looked at each other, and it was with that glance that two similar beings discovered and recognized one another. I asked her, "How long have you been letting your hair grow?" She smiled and said, "And how long ago did you cut yours?"

In the story "Trenzas," María Luisa Bombal (that marvelous writer of our adolescence) says that hair symbolizes the intimacy of shared experiences. That encounter changed our lives; it was as if our tresses, dark and light, had become interwoven in order to exemplify the course of those lives.

Emma and I conversed, ate ice cream, confessed our lives and our loves in a few brief minutes, and promised to meet again the next day. I returned home that afternoon filled with the incredible happiness of having found a treasure and, above all, a friend who had not begun by asking me the question that had plagued my childhood: Are you Jewish or Chilean?

On the second day, Emma and I continued our conversation. She told me of her passion for history, her domineering father who had sent her to a school run by sinister nuns, and her mother who wept in dark rooms. I spoke to her of my family, peaceful beings, practiced readers. I told her how my mother and grandmother cried both when they received letters from Vienna and when they stopped receiving them.

Emma confessed that I was the first Jewish girl that she had ever really known. I asked her, "Does it surprise you that I don't have a big hooked nose? Or that I don't have horns?" She looked at me, then winked a dark, sparkling eye and kissed my head. That kiss meant so much to me. Promise, hope, revelation. We swore to each other, as young girls swear, to write to one another, to tell each other of our lives, and to be a mutual source of comfort throughout the years.

These letters, written over the course of more than thirty years, reflect our friendship, dreams, and concerns. In this collec- 
tion we have chosen letters that we found most significant, beau$\mathrm{xi}$ tiful, and memorable. Some of them are exactly as they were originally written. Others have been edited not only for greater clarity but also in order to emphasize what we as adults have found to be central to our lives. A few of the letters began as sentence fragments or paragraphs upon which we have elaborated.

Our purpose in this collection is not to reveal specific facts and exact dates. Thus several gaps exist in the chronology. The lack of letters during those gaps lays them bare, demonstrating that very often life, like history, cannot be measured by means of chronological events or concrete texts, but instead is measured by means of memories, instances that make an impression, that leave prints but yet allow our memory to flow freely. It is not our intention to reveal every intimate detail of our lives, but rather to permit the reader to view specifics that profoundly shaped our experiences.

We hope that those who read these pages imagine us as two travelers on parallel routes. Two writers - one of poetry, the other of prose - who communicate their truths through writing, through words. Our correspondence reveals the spaces in our lives. First appear the letters of our youth and our years in the university. Then the political situation that shook Chile in the seventies prompts a lapse in our correspondence. The letters begin again once both Emma and I relocate to the United States - Emma in Nevada and California, and I in Indiana and New England.

Our personal lives, the history of our marriages and children, do appear in our correspondence, but for us the experience that unites us and that we want to share with you is the experience of exile, of belonging neither in Chile nor in the United States - the experience of existing between two cultures and not feeling comfortable in either of them, of choosing the path of political activism, and uniting our destiny with that of other marginalized women.

We do not want this book to be a record of our personal afflictions. Rather we present it as a history shared by thousands of others of our generation. It is the history of those from the Southern Hemisphere who were forced into exile for the crime of being young and wanting to change the world. We are the fortunate ones, for we survived, thanks to the love that surrounded us 
and to our passionate struggle for social justice. The two of us are products of the sixties and seventies, which were perhaps the most marvelous and disastrous epochs in the history of Latin America. We attended schools and universities in order to change the world. We listened to Victor Jara and Violeta Parra until the early hours of the morning, and the world, the streets, and our city belonged to us. With the arrival of dictatorships to Chile, Argentina, and Uruguay, Emma and I would never be the same. We lost not only a country but the dream of an entire continent: our generation's dream.

We came to this other America in search of refuge and freedom, all the while knowing that the CIA had helped topple the government of Salvador Allende, someone we had admired and who now is reborn in the presidency of Ricardo Lagos.

Amigas represents and reflects our carefree years of long vacations at the beach and in the countryside. But that external, superfluous existence slowly gives way to an exploration of the most profound issues of our reality: social prejudice within the Chilean as well as the Argentine culture, discrimination against women, and the machismo that inundated our lives. These letters that we are sharing with you are our obsessions and our treasures. They are the clearest reflections, not only of our souls but also of the times in which we were fated to live.

Many times we have wondered why we survived, how it had been possible to bear our complex emotional burdens for dozens of years. The answer is simple. Our letters, the letters that you see here, are enchanted threads held in place by means of the words that we send one another for the purpose of sharing the lives stolen from us through events that stripped us of our souls, of the land of our memories, our language, and our precious identity.

These letters were written in Spanish. The reader will observe that the voices are transformed with the passing of the years. The translator has been faithful to their colloquial style. But, more important, she has sought to re-create in the English language our Latina reality, a reality submerged in the spaces of affection, passion, and memory.

Emma and I, I and Emma, have traveled down a long road. I 
have let my hair grow and she has cut hers a little. My hair has darkened and gray has lightened hers. We have given birth to children, we have shared the dreams and fears of being Americans and foreigners, but we have essentially changed very little. We call one another frequently, two or three times a week. We begin our conversations in absolute seriousness, discussing university politics or human rights (for us, a constant topic), but quickly we begin to remember things we did in El Quisco, in Santiago, or in Reno, and we then know that we have returned home. We have returned to the familiar territory of a shared youth. Memories are no longer distant; on the contrary, we seem to have a magic flying carpet that carries us to the voices of our first encounters. With Emma, I can be Chilean-Jewish and gringa, all those identities together, and with me, she can be Catholic, agnostic, ChileanArgentine, upper class, and popular. The friendship that exists between beings, a true friendship, should not judge but should be diaphanous and luminous. It should open the doors to understanding. As Violeta Parra sings in a song that Emma and I have heard together countless times, friendship should "alleviate the suffering of the soul." This is what our correspondence tries to alleviate, the suffering of the souls of two immigrant women in a society that accepts them and rejects them, but nevertheless permits them to tell their story.

- Marjorie Agosín

My parents brought us to Chile from Argentina so that we could see the Pacific Ocean and meet our grandparents who lived in the south. We were going to spend an unforgettable vacation in a country of wonders and then return again to our toys, house, and Italian grandparents who had settled in Mendoza. "One month, only one, four weeks, you can count them on a single hand," my father said when we were on the plane to Santiago, Chile, in March 1957. We stayed those four weeks and many more, until my little fingers were unable to determine their number. Then my parents stopped talking about Argentina and, slowly, silence 
xiv began to shroud our infantile, obsessive questions. They no longer spoke of going back, and we never returned to our toys or to the old house with red walls. We stopped being Argentines, like my mother, and from that moment we became Chilean tourists, travelers who visited my grandparents' country estate in Argentina once a year.

Almost a decade later, still lost in Wonderland, I found my friend Marjorie Agosín without looking for her, almost by accident, as happens with all the treasures that surprise us in life. From the first moment, our similarities brought us close together and our differences united us. Two adolescents, one Jewish and the other Catholic, both living the confusions of a society decayed because of its incomprehensible traditions ... they meet, their lives merge in an unconditional friendship, and they forge parallel roads while carrying throughout the world - and through timetheir backpacks heavy with thousands of memories.

Meeting young Marjorie was like penetrating the confines of another world. I had never known another human being who could talk more than me. I had never known another girl who invented stories and played with the contours of the real and the imaginary as well as Marjorie did (and still does). She had what I always dreamed of having, and I possessed what she longed to own. Or perhaps it was the reverse? I am not certain if it was because we wanted to have something else or to change what we had, but through our endless stories we felt united from the first moment we met.

I wrote to Marjorie on those days when life seemed full of hope, when the most pressing obligation I had was to get on my knees and pray, try not to chew the wafer after receiving communion, and obey the instructions of the Irish nuns. But I also wrote to her when I was confronted by the cruelty of a man who could do everything except learn how to be a father. I wrote her about the unyielding strength of my mother, who suffered more than anyone else I will ever meet, yet died truly giving thanks for her life. I would write to my friend Marjorie because by writing her, I would live. I not only survived those profoundly challenging years but, through the words of our letters, I was reborn. Every 
time I wrote I was reborn, again and again. I wrote in order to set down on paper my profound suffering, the pain that I used to imagine would leave my daily life if I could make the words that described it leave my pen. In those days, I thought that things that hurt you could be shed or dislodged, like shoes we had outgrown or useless baby teeth.

The years passed and the letters continued being sent from and received in all corners of the world. They always have been, and still are, letters. I have never been able to send a postcard to Marjorie. When I write to her I cannot jot down a few lines on paper . . . it has to be pages and pages. I dialogue with her in my imagination. More than writing to her, I talk to her with a pen in my hand. I allow the ink to draw images and illustrate moments, and I know with absolute certainty that Marjorie will decipher my drawings and understand my words.

Marjorie's letters always arrive to me on pastel papers, like the antique silks of her clothes, and scented with exotic perfumes like those one bathes in during nights of a full moon. . . She always places a keepsake from the beaches of Chile, a bar in Paris, or a square in Prague into the envelope. Marjorie's letters, more than letters, are poems. But I have not found this strange, since for Marjorie life is a poem, and she lives it intensely, like the passionate poems that she writes.

The topics of our letters continued evolving along with the changing paths that Marjorie and I have followed. Roads parallel and distant, narrow and dark. Exile changed our lives, and our lives altered the words in our letters. The political situation in Chile forced us to seek the road to exile, and since that moment we have wandered another's land searching for a peaceful, tender encounter ... with our adopted country as well as with the homeland of our earlier dreams. Amid the confusion, Marjorie is the lighthouse that draws me near, guides me, and transports me to Chile on dark, stormy days. But she is also the soft, calm earth that affirms my roots in the dry soil of this country in the North. And so in this eternal exile we two, hand in hand across the distance, find pleasure in life, suffer its disappointments, cheat death, and win battles that we have never learned how to lose. 

liked to have known about me before I depart on my final eternal journey, but I am convinced that they should be made public as a testimony of the life of women in Latin America, and of the Latina immigrants who live in the United States. The histories interwoven in our correspondence are not exceptions, they are the norm. These episodes from the lives of Marjorie and Emma are part of a voluminous tome of common histories that have been lived and continue to be lived by Latin American women, from our grandmothers to our daughters.

In the pages of this epistolary work about two friends who seem to have known one another always, there are letters that follow the passing of the years and obey a chronological order, but there are also long spaces of silence that separate events and places. As we were editing the book, we wanted to present a history broken into fragments, into moments that gave form to our lives, instead of merely making a sequence of letters that constantly came and went, across the continents, rhetorically asking questions that we have yet to fully answer.

Many years have passed since we first met and since that first letter I sent to a young Marjorie in Chile. Upon beginning the new millennium, I wrote again to Marjorie from Chile, this time from distant Patagonia. I realized as I was writing the letter that all those trips we've made throughout the years, all the times we have bid farewell to Chile, were rehearsals for the final chapter that we will have to write someday. Calm and resigned, I finally took my leave of that long, narrow land in the south and returned to the North knowing and accepting that a part of my heart never crossed the Andes, but rather remains eternally suspended above the confines of the Chilean sea. And the other part comes with me to continue life in this country that I now miss and deeply adore. It could not have been a coincidence that, while I was being processed through customs at the Los Angeles airport after returning from Chile in January 2000, the young Latino agent handed my passport back to me, fixed his dark eyes on mine, and, with a smile of complicity, said in perfect Spanish, "Bienvenida a su patria, Sra. Sepúlveda."

\section{- Emma Sepúlveda}


DAMIgAS 
THIS PAGE INTENTIONALLY LEFT BLANK 